\title{
Ion-exchange Resin Catalyzed Esterification of Lactic Acid with Isopropanol: a Kinetic Study
}

\author{
Amrit Pal Toor *, Mamta Sharma, Sakshi Thakur, and R.K.Wanchoo \\ University Institute of Chemical Engineering \& Technology \\ Panjab University, Chandigarh-160014, INDIA
}

Received: 19th January 2011; Revised: 16th March 2011; Accepted: 16th March 2011

\begin{abstract}
The kinetic behavior of esterification of lactic acid with isopropanol over an acidic cation exchange resin, Amberlyst 15, was studied under isothermal condition. Isopropyl lactate synthesized in this reaction is an important pharmaceutical intermediate. The experiments were carried out in a stirred batch reactor in the temperature range of 323.15 to $353.15 \mathrm{~K}$. The effect of various parameters such as temperature, molar ratio and catalyst loading was studied. Variation in parameters on rate of reaction demonstrated that the reaction was intrinsically controlled. Kinetic modeling was performed using Eley-Rideal model which acceptably fits the experimental data. The activation energy was found to be $22.007 \mathrm{~kJ} / \mathrm{mol}$ and frequency factor was $0.036809 \mathrm{l}^{2} \mathrm{~g}^{-1} \mathrm{~mol}^{-1} \mathrm{~min}^{-1}$ for forward reaction. The value of entropy for the forward reaction was found to be $182.317 \mathrm{~J} \mathrm{~K}^{-1} \mathrm{~mol}^{-1}$. C 2011 BCREC UNDIP. All rights reserved
\end{abstract}

Keywords: Heterogeneous catalysis; Esterification; Lactic acid: Ion exchange resin; Amberlyst-15

Esterification is a well-known process and a number of industrially important chemicals such as methyl, ethyl and butyl esters, alkyl t-butyl ethers (MTBE and ETBE) are produced using such reactions [1,2]. Esterification is very widely understood and extensively used reaction, especially in the pharmaceutical, chemical industries such as solvents of paints, adhesives, plasticizers, flavors and fragrances, pesticides and emulsifiers, perfumery, food industries and in the preparation of biodiesel from lower quality feedstock [3,4]. Derivatives of some esters are useful as chemical intermediates and monomers for resins and high molecular weight polymers [5].

Esterification of carboxylic acids with alcohols in presence of acid catalysts has been extensively investigated. Typical homogenous catalysts like $\mathrm{H}_{2} \mathrm{SO}_{4}, \mathrm{HCl}$ and $\mathrm{ClSO}_{3} \mathrm{OH}$ are used but due to their miscibility with the reaction medium, separation becomes a problem, hence ion exchange resins are preferred over homogeneous acids due to ease of product separation and catalyst recovery [6]. The drive to develop green processes has led to the development of solid acid catalysts to a significant increase in research activities both in academic and industrial sections. These materials can replace the corrosive liquid acids currently used in many industries [7].Therefore heterogeneous catalyst become an attractive alternative catalyst which is non-polluting, non corrosive and has long activity life. Scientific literature contains some reports on the use of heterogeneous acid catalysts

\footnotetext{
* Corresponding Author.

E-mail address: aptoor@yahoo.com (A.P. Toor)
} 
for esterification. The most popular solid acid catalysts used to produce esters have been ionexchange organic resins, such as amberlyst 15, Amberlyst 35, Amberlyst 36, Dowex $50 \mathrm{~W}$ etc [815].In the recent years a lot of studies were subjected to ion-exchange resins, which are distinguished among solid-state catalysts by their reactivity and selectivity. They are also relatively cheap and could be reused many times [9-16]

Lactic acid and their esters are used in food industry for preservation and flavoring purposes, as well as in the pharmaceutical and cosmetic industries [9]. Sanz et al [17, 18] studied the ion exchange resin catalyzed esterification of lactic acid with methanol and ethanol and reported that Amberlyst 15 is most suitable catalyst for the reaction. Zang et al [19] investigated the esterification of lactic acid with ethanol in the presence of five different cation exchange resins. Their investigations indicated that pseudo homogeneous second order model was the most appropriate model to describe the kinetic behavior. Studies on esterification reaction of lactic acid with isopropanol has been done by Yadav et al [3] over Amberlyst 36 at higher molar ratios of reactants (i.e. lactic acid to iso-propanol upto 1:44).

They also studied the application of different heterogeneous catalyst such as Amberlyst 15, Indion 130, Amberlite-120, Dowex $50 \mathrm{~W}$, and Filtrol-44. Amongst these Amberlyst 15, Amberlyst 36 and Indion-130 were observed to be most effective. By using the large excess of one of the reactants the reaction yield of other compound can be enhanced but because of the presence of the large excess of one of the reactant, the recovery of the product and the reactant becomes more expensive [18].

The present study aims at to provide insight into the kinetics of the esterification of lactic acid with isopropanol over amberlyst 15 at low molar ratios and compare the results with data available for higher molar ratios [3] and to investigate the effect of reaction temperature, catalyst loading and molar feed ratio.

\section{Experimental}

\subsection{Chemicals and Catalysts}

All chemicals used in the study were obtained from the reputed firms. Lactic acid (Qualigens fine chemicals, Mumbai), 2-Propanol (Qualigens fine chemicals, Mumbai), Ion exchange resin, Amberlyst 15 (Roam and Hass, Pennsylvania, USA), Sodium Hydroxide (s.d. fine chemicals ltd., Boisar), Phenolphthalein indicator, (Qualigens fine chemicals, Mumbai)

\subsection{Apparatus and Procedure}

Reaction kinetics was studied in a three-necked glass reactor of $500 \mathrm{ml}$ capacity operating in a batch mode. A reflux condenser was used to avoid the loss of volatile compounds. The catalyst was suspended in the reaction mixture with the help of stirrer. A simple pretreatment was given to the catalyst to convert it to acid form. The catalyst was initially washed with distilled water four to five times and was dried at ambient conditions for 4-5 hrs. Further the catalyst was washed by dipping in $0.1 \mathrm{~N}$ hydrochloric acid solution for half an hour. This solution was then filtered to separate the catalyst and dried at atmospheric conditions for about $48 \mathrm{hrs}$. In all the experiments, a known amount of lactic acid and the catalyst were charged into the reactor and heated to the desired temperature. Temperature inside the reactor was controlled within the accuracy of $\pm 0.5 \mathrm{~K}$. All of the reactants charged in the reactor were volumetrically measured. The progress of the reaction was followed by withdrawing samples at regular intervals, small enough to consider them negligible compared to the volume of the reaction mixture.

\subsection{Analysis}

To measure the concentration of unreacted acid in the reaction mixture, each sample was analyzed volumetrically by $1 \mathrm{~N} \mathrm{NaOH}$ as titrant and phenolphthalein as an indicator.

\section{Results and Discussion}

The esterification reaction of lactic acid with isopropanol was studied in a batch reactor in the presence of acidic ion exchange resin catalyst; Amberlyst 15.The kinetics of esterification of lactic

Table 1. Experimental conditions and range of fractional conversion obtained

\begin{tabular}{lllcc}
\hline $\begin{array}{l}\text { S.n } \\
\text { o. }\end{array}$ & $\begin{array}{c}\text { Reaction } \\
\text { Tempera- } \\
\text { ture (K) }\end{array}$ & $\begin{array}{c}\text { Molar } \\
\text { Ratio } \\
(M)\end{array}$ & $\begin{array}{c}\text { Catalyst } \\
\text { Loading } \\
\left(\mathrm{kg} / \mathrm{m}^{3}\right)\end{array}$ & $\begin{array}{c}\text { Range of } \\
\text { Conversion } \\
X_{A}\end{array}$ \\
\hline 1 & 323 to 353 & 1.5 & 11.84 & 0.12 to 0.30 \\
& & 1.5 & $\begin{array}{c}4.73 \text { to } \\
11.84\end{array}$ & 0.12 to 0.36 \\
& 353 & 11.84 & 0.15 to 0.42 \\
3 & 353 & 1 to 3 & 11.84 \\
\hline
\end{tabular}


acid was studied at different temperatures from 323-353 K, different molar ratios (M i.e. molar ratio of isopropanol to lactic acid) and varying the catalyst loading as given in table 1 .

\subsection{Kinetics}

Esterification of lactic acid with iso-propanol can be represented as:

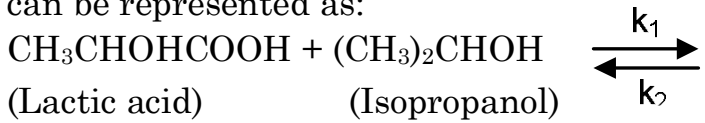

$$
\begin{aligned}
& \mathrm{CH}_{3} \mathrm{CHOHCOO}\left(\mathrm{CH}_{3}\right)_{2} \mathrm{CH}+\mathrm{H}_{2} \mathrm{O} \\
& \text { (Isopropyl lactate) (Water) }
\end{aligned}
$$

Reaction mechanism for this reaction can be well studied by Eley-Rideal model [20] that is the reaction takes place between adsorbed molecules of alcohol and the molecules of acid in bulk solutions. The adsorption of ester is reported to be negligible [20-22]. Hence the rate equation is:

$$
\frac{d X_{A}}{d t}=\frac{k_{1} C_{A 0}(w / V)\left[\left(1-X_{A}\right)\left(M-X_{A}\right)-\left(X_{A}\left(N+X_{A}\right) / K_{e}\right)\right]}{1+K_{B} C_{A 0}\left(M-X_{A}\right)+K_{W} C_{A O}\left(N+X_{A}\right)}
$$

As stated in the literature the value of $\mathrm{K}_{\mathrm{B}}, \mathrm{K}_{\mathrm{w}}$ were found to be negligible for esterification of lactic acid with lower alcohols [3, 23].

As in absence of any product initially $\mathrm{N}=0$, Equation 2 reduces to

$$
\frac{d X_{A}}{d t}=k_{1} C_{A O}(w / V)\left[\left(1-X_{A}\right)\left(M-X_{A}\right)-\frac{X_{A}^{2}}{K_{e}}\right]
$$

Putting $k_{1} C_{A 0}(w / V)=k$ in equation 3 and then integrating the equation:

$$
\left[\frac{\tanh ^{-1} \frac{K_{e}\left(M-2 X_{A}+1\right)+2 X_{A}}{\sqrt{K_{e}} \sqrt{K_{e}(M+1)^{2}+4 M}}}{\frac{\sqrt{K_{e}(M-1)^{2}+4 M}}{2 \sqrt{K_{e}}}}\right]=k t+C
$$

Which can be written as:

$$
Y=k t+C
$$

where

$$
Y=\left[\frac{\tanh ^{-1} \frac{K_{e}\left(M-2 X_{A}+1\right)+2 X_{A}}{\sqrt{K_{e}} \sqrt{K_{e}(M+1)^{2}+4 M}}}{\frac{\sqrt{K_{e}(M-1)^{2}+4 M}}{2 \sqrt{K_{e}}}}\right]
$$

The value of $\mathrm{C}$ at $\mathrm{t}=0, \mathrm{X}_{\mathrm{A}}=0$

$$
C=\frac{2 \sqrt{K_{e}} \tanh ^{-1}\left[\frac{K_{e}(M+1)}{\sqrt{K_{e}} \sqrt{K_{e}(M-1)^{2}+4 M}}\right]}{\sqrt{K_{e}(M-1)^{2}+4 M}}
$$

\subsection{Effect of catalyst loading on reaction}

The catalyst loading was varied from $4.73 \mathrm{~kg} / \mathrm{m}^{3}$ to $14.21 \mathrm{~kg} / \mathrm{m}^{3}$ (of the reaction mixture), which corresponds to 1 to $3 \%$ (Weight/volume) of reaction mixture at a temperature of $353.15 \mathrm{~K}$ and molar ratio, $\mathrm{M}$ of 1.5. Fig.1 illustrates the variation in fractional conversion $\left(\mathrm{X}_{\mathrm{A}}\right)$ of lactic acid for different catalyst loading at specified temperature. Fractional conversion was found to be increasing with the increase in catalyst loading. Equilibrium conversion increases with increase in catalyst loading which could be due to more number of available acid sites for the reaction. For reactions catalyzed by the amberlyst series resins, the intraparticle diffusional resistances are usually negligible [20].

Thus typical second order rate equation was used as given in Equation (4) to find the values of rate constant k. Fig 2.shows the plot of $\mathrm{Y}$ vs. time at different catalyst loading is straight line and the slope of these lines gives the rate constant. The rate constants thus calculated at different catalyst loading were plotted with catalyst loading (w) as shown in Fig.3. It is seen that the rate is linearly proportional to $\mathrm{w}$ (weight of the catalyst) which is in accordance with the observation reported in [3, 20 , and 22].

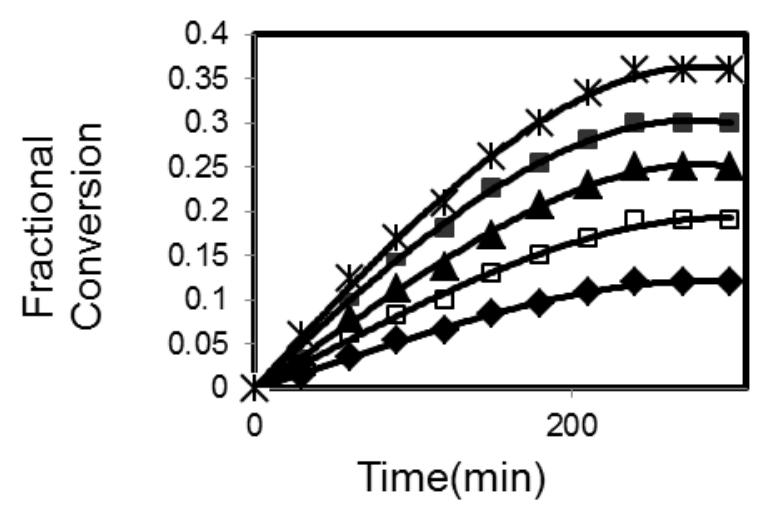

Figure 1. Lactic acid conversion vs. time for different catalyst loading of Amberlyst 15, $4.73 \mathrm{~kg} / \mathrm{m}^{3}$,

$\square 7.11 \mathrm{~kg} / \mathrm{m}^{3}, \boldsymbol{\Delta} 9.47 \mathrm{~kg} / \mathrm{m}^{3}, \boldsymbol{\bullet}, 11.84 \mathrm{~kg} / \mathrm{m}^{3}$, a 14.21 $\mathrm{kg} / \mathrm{m}^{3}$ (Temperture:353 $\mathrm{K}$ and $\mathrm{M}=1.5$ ) 


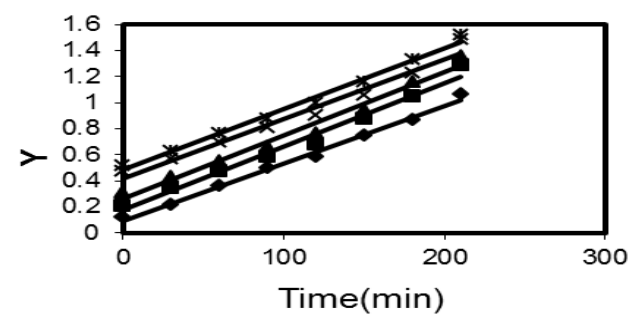

Figure 2. Effect of catalyst loading. Y vs.time (min), $4.73 \mathrm{~kg} / \mathrm{m}^{3}$, ㅁ, $7.11 \mathrm{~kg} / \mathrm{m}^{3}, \boldsymbol{\Lambda} 9.47 \mathrm{~kg} / \mathrm{m}^{3}$, п, $11.84 \mathrm{~kg} / \mathrm{m}^{3}$, a $14.21 \mathrm{~kg} / \mathrm{m}^{3}$ (Temperture: $353 \mathrm{~K}$ and $\mathrm{M}=1.5)$

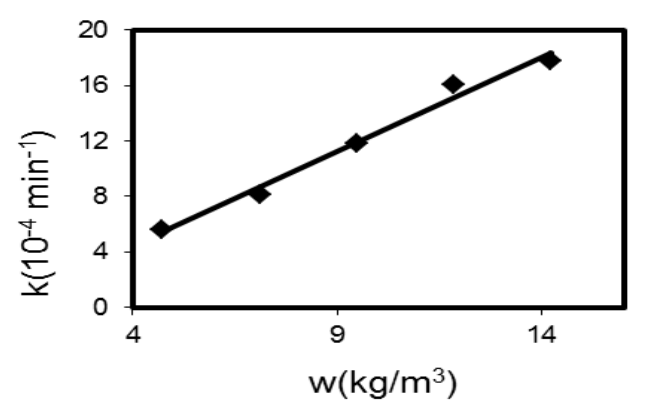

Figure 3. Reaction rate constant (k) vs. catalyst loading (w) for reaction of lactic acid with isopropanol at temperature $353 \mathrm{~K}$ and $\mathrm{M}=1.5$

\subsection{Effect of Temperature}

To study the effect of the temperature is important since it is useful in calculating the activation energy of the reaction. The effect of temperature on conversion under otherwise similar conditions was studied in the range of 323.15 to $353.15 \mathrm{~K}$ (Fig.4). Lui and Tan [21] have reported that ester conversion is dependent on the temperature and conversion increases with the increase in temperature. The plots $\mathrm{Y}$ vs. time gives a straight line as shown in Fig 5 and the rate constants for forward reaction at different temperatures were calculated using whole data and the values are tabulated in table 2 . Temperature dependency of the specific reaction rate constant was expressed in terms of Arrhenius equation, which follows,

$$
k_{1}=k_{o} \exp \left(\frac{-E_{1}}{R T}\right)
$$

Where, $\quad k_{0}=$ Frequency factor; $E_{1}=$ Activation energy, and $\mathrm{R}=$ Gas constant (8.314 $\left.\mathrm{JK}^{-1} \mathrm{~mol}^{-1}\right)$

For the linear plot of $-\mathrm{ln} \mathrm{k}_{1}$ versus to $1000 / \mathrm{T}$ Fig.6, activation energy $\left(\mathrm{E}_{1}\right)$ and frequency factor $\left(\mathrm{k}_{0}\right)$ for the forward reaction was determined. $\mathrm{E}_{1}$
Table 2. Rate constant values at different temperature

\begin{tabular}{cc}
\hline Temperature $(K)$ & $\begin{array}{c}\text { Rate Constant } k_{1} \\
\left(\mathrm{~mol}^{-1} \mathrm{~g}^{-1} \mathrm{~min}^{-1}\right)\end{array}$ \\
\hline 323.15 & $1.058 \times 10^{-5}$ \\
333.15 & $1.235 \times 10^{-5}$ \\
343.15 & $1.588 \times 10^{-5}$ \\
353.15 & $2.117 \times 10^{-5}$ \\
\hline
\end{tabular}

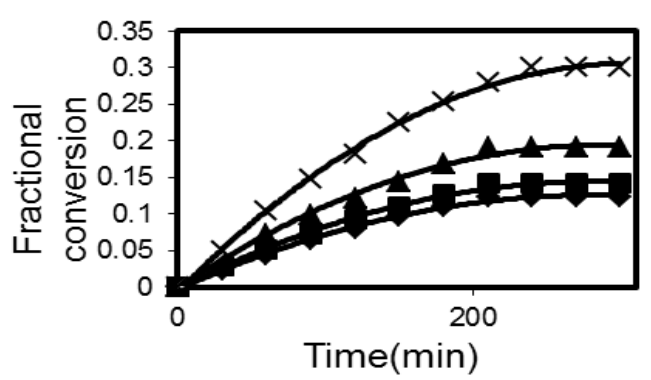

Figure 4. Lactic acid conversion versus Time for different temperatures for 11.84 $\mathrm{kg} / \mathrm{m}^{3}$ catalyst loading at $\mathrm{M}=1.5, \mathrm{x} 353 \mathrm{~K}$;

\ $343 \mathrm{~K} ; \boldsymbol{\bullet}, 333 \mathrm{~K} ;-323 \mathrm{~K}$

was found to be $22.0079 \mathrm{~kJ} / \mathrm{mol}$ and $\mathrm{k}_{0}$ was found to be $3.681^{*} 10^{-2} \mathrm{l}^{2} \mathrm{~g}^{-1} \mathrm{~mol}^{-1} \mathrm{~min}^{-1}$. The increase in the value of the equilibrium constant with an increase in temperature indicates that the reaction is endothermic in nature. Reaction enthalpy $\left(\Delta \mathrm{H}^{\circ}\right)$ and reaction entropy $\left(\mathrm{S}^{\circ}\right)$ for forward reaction were obtained from Equation (6) by plotting $\ln \mathrm{K}$ against 1000/T [7].

$$
\ln K=\frac{\Delta H^{0}}{R T}+\frac{\Delta S^{o}}{R}
$$

Where $\mathrm{K}=$ equilibrium constant, $\mathrm{R}=$ universal gas constant. The positive value of enthalpy suggests that the esterification reaction is endothermic in nature. The linear plot yields $\Delta \mathrm{S}$ 。 $=182.317 \mathrm{~J} \mathrm{~K}^{-1} \mathrm{~mol}^{-1}$ and $\Delta \mathrm{H}^{\circ}=70.022 \mathrm{~kJ} \mathrm{~mol}^{-1}$

\subsection{Effect of molar ratio}

The initial molar ratio of lactic acid to isopropanol was varied from 1 to 3 for the esterification reaction at a catalyst loading of 11.84 $\mathrm{kg} / \mathrm{m}^{3}$ at $353 \mathrm{~K}$. As can be seen from Fig 7 that the equilibrium conversion increases with the initial reactant molar ratio. From this figure it can be 


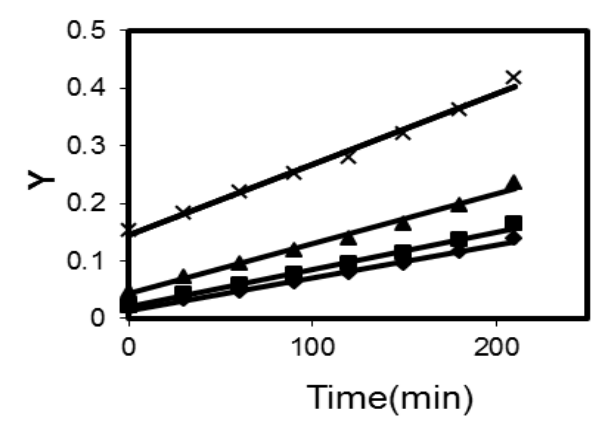

Figure 5. Y versus Time for different temperatures for $11.84 \mathrm{~kg} / \mathrm{m}^{3}$ catalyst loading at $\mathrm{M}=1.5, \times$ $353 \mathrm{~K} ; \mathbf{\Delta} 343 \mathrm{~K}$ - $333 \mathrm{~K} ; \quad 323 \mathrm{~K}$

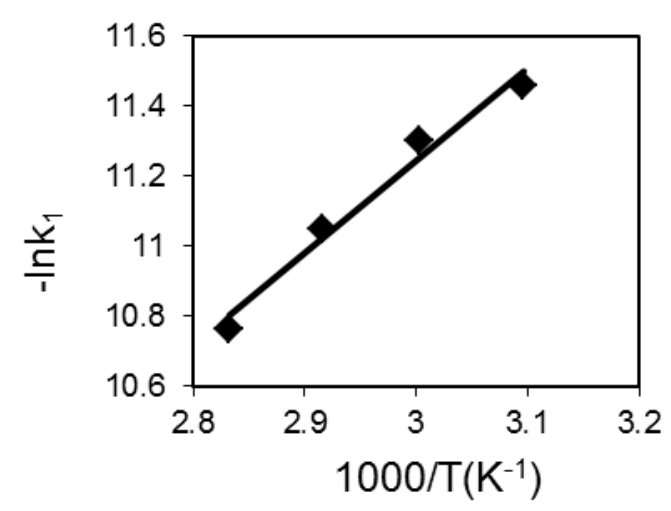

Figure 6. Arrhenius plot of $\ln \mathrm{k}_{1}$ vs. 1000/ $\mathrm{T}, \mathrm{M}=1.5(\mathrm{LA}: \mathrm{IP})$, catalyst loading 11.84 $\left.\mathrm{kg} / \mathrm{m}^{3}\right)$

observed that equilibrium conversion for molar ratio $\mathrm{M}=1$ is $15 \%$ which increases up to $42 \%$ for molar ratio $\mathrm{M}=3$. In Fig 8 the conversions obtained at lower initial reactant molar ratios for the esterification reactions of lactic acid with isopropanol was compared with conversions reported in the literature at higher molar ratios [3].The use of large excess of one of reactants the reaction yield is increased but due to presence of large excess of one of the reactant, the recovery of the product and cost of the reactant increases, so trade off between the cost recovery and conversion has to be addressed.

The experimental data was fitted in the Equation (2) and the values of $K_{B}$ and $K_{W}$ were found to be negligible. The experimented values of fractional conversion were compared with the values calculated from the Equation (4) taking $\mathrm{k}=$ $\mathrm{k}_{0} \mathrm{e}^{-\mathrm{E} / \mathrm{RT}}$ as shown in Fig 9. The predicted values of $\mathrm{X}_{\mathrm{A}}$ are in close agreement with the experimental values within the range of experimental error.

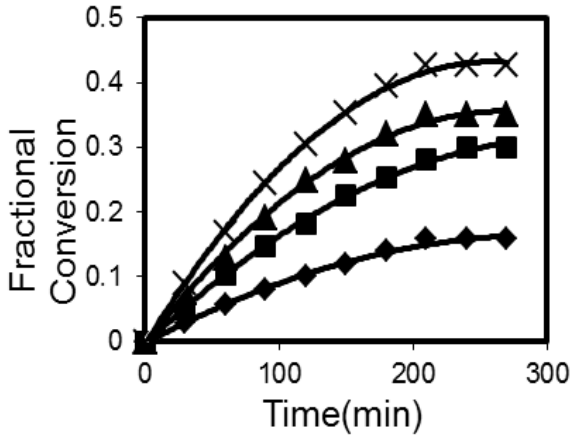

Figure 7. Lactic acid conversion versus Time for different molar ratios for $11.84 \mathrm{~kg} / \mathrm{m}^{3}$ catalyst loading at $353 \mathrm{~K}, \times 3 ; \boldsymbol{\Delta} 2 ;$ - $1.5 ; 1$

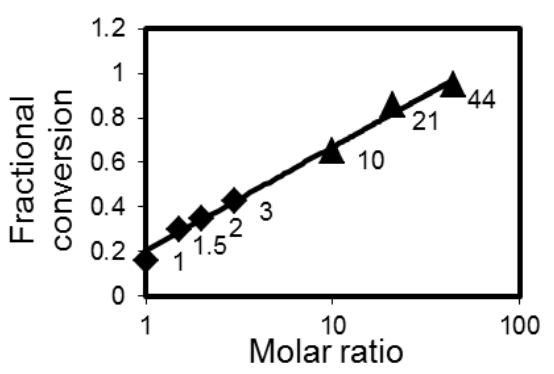

Figure 8. Fractional conversion $\left(\mathrm{X}_{\mathrm{A}}\right)$ versus molar ratio at temperature $353 \mathrm{~K}$. $\mathbf{\Delta}$ [3] (at catalyst loading of $\left.27.27\left(\mathrm{~kg} / \mathrm{m}^{3}\right)\right)$, (present experimental values at catalyst loading of $\left.11.84\left(\mathrm{~kg} / \mathrm{m}^{3}\right)\right)$

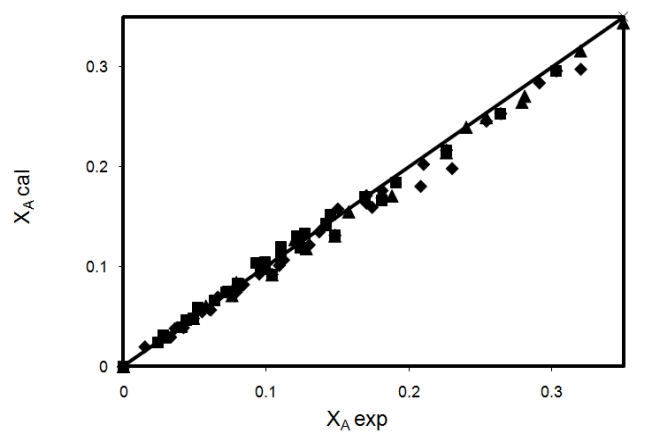

Figure 9. Fitting calculated to experimental data for Esterification of lactic acid with isopropanol over Amberlyst 15 as catalyst. $\boldsymbol{\Lambda}$; molar ratio (1to 3)at $11.84 \mathrm{~kg} / \mathrm{m}^{3}$ catalyst loading and $353 \mathrm{~K}$ temperature, - ;Temperature (323 to $353 \mathrm{~K}$ ) at $11.84 \mathrm{~kg} /$ $\mathrm{m}^{3}$ and 1.5 molar ratio , , Catalyst loading(4.73 to $\left.14.21 \mathrm{~kg} / \mathrm{m}^{3}\right)$ at $353 \mathrm{~K}$ and 1.5 molar ratio 


\section{Conclusions}

Kinetic behavior has been investigated experimentally for the synthesis of isopropyl lactate using Amberlyst 15 as a catalyst. The experimental data were obtained in a batch reactor within the temperature range ( $323.15 \mathrm{~K}$ to 353.15 $\mathrm{K})$. Reaction entropy and enthalpy for the esterification of lactic acid with isopropanol over Amberlyst 15 at different temperatures were found to be $\Delta \mathrm{S}^{\circ}=182.317 \mathrm{JK}^{-1} \mathrm{~mol}^{-1}$ and $\Delta \mathrm{H}^{\circ}=70.022$ $\mathrm{kJmol}^{-1}$. Activation energy and frequency factor for the forward reaction were found to be 22.0079 $\mathrm{kJ} / \mathrm{mol}$ and $0.036809 \mathrm{l}^{2} \mathrm{~g}^{-1} \mathrm{~mol}^{-1} \mathrm{~min}^{-1}$ respectively. The reaction is endothermic in nature. The reaction kinetics was well represented by EleyRideal model. The reaction rate increased with the increasing temperature of the reaction, weight of the catalyst, and molar ratio. The experimental work showed that esterification of lactic acid with isopropanol can successfully be carried out at low molar ratio also.

\section{Acknowledgements:}

We gratefully acknowledge the financial support received from UGC (Govt of India)vide project no. F.No.37-295/2009 (SR)

\section{Notations}

\begin{tabular}{|c|c|}
\hline $\mathrm{k}_{1}$ & $\begin{array}{l}\text { Rate constant for esterification } \\
\text { reaction }\end{array}$ \\
\hline $\mathrm{C}_{\mathrm{A} 0}$ & $\begin{array}{l}\text { Initial concentration of lactic acid } \\
(\mathrm{mol} / \mathrm{lt})\end{array}$ \\
\hline M & Molar ratio \\
\hline $\mathrm{X}_{\mathrm{A}}$ & Fractional conversion \\
\hline $\mathrm{w}$ & Weight of the catalyst $\left(\mathrm{kg} / \mathrm{m}^{3}\right)$ \\
\hline $\mathrm{V}$ & $\begin{array}{l}\text { Volume of the reaction } \\
\text { mixture(litre) }\end{array}$ \\
\hline $\mathrm{K}_{\mathrm{e}}$ & Equilibrium rate constant \\
\hline $\begin{array}{c}\mathrm{K}_{\mathrm{w}} \\
\text { water }\end{array}$ & Adsorption rate constant for \\
\hline $\mathrm{K}_{\mathrm{B}}$ & $\begin{array}{l}\text { Adsorption rate constant for } \\
\text { alcohol }\end{array}$ \\
\hline$\Delta \mathrm{H}^{\circ}$ & Enthalpy of the reaction $\left(\mathrm{kJmol}^{-1}\right)$ \\
\hline$\Delta \mathrm{S}^{\circ}$ & Entropy of the reaction $\left(\mathrm{JK}^{-1} \mathrm{~mol}^{-1}\right)$ \\
\hline$k_{0}$ & Frequency factor $\left(1^{2} \mathrm{~g}^{-1} \mathrm{~mol}^{-1} \mathrm{~min}^{-1}\right)$ \\
\hline$E_{1}$ & Activation energy $\left(\mathrm{kJmol}^{-1}\right)$ \\
\hline
\end{tabular}

\section{References}

[1] Carey, F., Sundberg. R., 1990., Reaction and synthesis: Advanced Organic Chemistry, 3rd Edition, New York.

[2] Phalak, C. A., 2004, Reaction Engineering studies in ion exchange resin catalyzed esterification reactions", Thesis submitted to National chemical Laboratory, Pune, India.

[3] Yadav,G.D.,Kulkarni,H.B.,2000,Ion exchange resin catalysis in the synthesis of isopropyl lactate, Reactive Function Polymer, 44:153-165 .

[4] Alime,I., Hosgun L.,2007,Kinetics of synthesis of isobutyl propionate over amberlyst 15", Turkish Journal of Chemistry,31:493-499 .

[5] Mcketta, J., 2002 Encyclopedia of Chemical Processing and Design”, CRC Press LLC,69:262.

[6] Ayyappan,K.R.,Toor.A.P., Gupta R., Bansal A., Wanchoo R.K., 2009, Catalystic hydrolysis of Ethyl Acetate using cation exchange resin (Amberlyst 15) : A kinetic study", Bulletin of Chemical Reaction Engineering \& Catalysis, 4:16-22.

[7] Viswanathan, S., Varadarajan, B., 2004, Esterification by Solid Acid Catalysts-a Comparison, Journal of Molecular Catalysis A: Chemical, 223: 143-147.

[8] Ma, F.R., Hana, M.A., 1999, Biodiesel production: a review, Bioresource Technology, 70:1-15.

[9] Gelbard, G., 2005, Organic Synthesis by Catalysis with Ion-Exchange Resins", Industrial \& Engineering Chemistry Research, 44(23): 8468-8498.

[10] Mazzotti, M., Neri, B., Gelosa, D., Kruglov, A., Morbidelli, M., 1997, Kinetics of Liquid-Phase Esterification Catalyzed by Acidic Resins, Industrial \& Engineering Chemistry Research, 36(1):3-10.

[11] Pöpken,T., Götze, L., Gmehling, J., 2000, Reaction Kinetics and Chemical Equilibrium of Homogeneously and Heterogeneously Catalyzed Acetic Acid Esterification with Methanol and Methyl Acetate Hydrolysis, Industrial \& Engineering Chemistry Research, 39(7):2601-2611.

[12] Lee, M. -J., Chiu, J.-Y., Lin, H., 2002, Kinetics of Catalytic Esterification of Propionic Acid and n-Butanol over Amberlyst 35, Industrial \& Engineering Chemistry Research, 41(12):2882-2887.

[13] Lee, M.-J., Wu, H.-T., Lin, H., 2000, Kinetics of Catalytic Esterification of Acetic Acid and Amyl Alcohol over Dowex, Industrial \& Engineering Chemistry Research, 39( 11):4094-4099.

[14] Alexandratos, S.D., 2009, Ion-Exchange Resins: A Retrospective from Industrial \& Engineering Chemistry Research, Industrial \& Engineering Chemistry Research, 48(1): 388-398.

[15] Teresa, W., Miroslaw, G., Jerzy S., Mariusz,W., 2010, Liquid -phase esterification of methacrylic acid with methanol catalyzed by heteropolyacids, International Journal of Chemical Reactor Engineering, 8:A68.

[16] Mehmet, R.A., Alime,Ç., 2003, Kinetics study of Esterification of Acetic acid with isobutanol in the presence of amberlite catalyst", Applied Catalysis A: General, 239:141-148. 
[17] Sanz, M.T, Murga, R, Beltran, S., 2002, Recovery of lactic acid by batch reactive distillation, Industrial \& Engineering Chemistry Research, 41:512-517.

[18] Patrica, D., Maria, T.S, Sagrario, B., 2007, Kinetic study for esterification of lactic acid with ethanol and hydrolysis of ethyl lactate using an ion-exchange resin catalyst, Chemical Engineering Journal, 126:111-118.

[19] Zhang, Y., Yang, Ma L., 2004, Kinetics of Esterification of lactic acid with Ethanol catalyzed by cation-exchange resins, Reactive Functional Polymer,61:101-114.

[20] Darge, O., Thyrion, F.C., 1993, Kinetics of the liquid phase synthesis and hydrolysis of butyl lactate catalysed by cation exchange resin, Journal of Chemical Technology and Biotechnology,58:351-357 .
[21] Liu, W.T., Tan, C.S., 2001, Liquid-phase esterification of propionic acid with n-butanol, Industrial \& Engineering Chemistry Research, 44:3281-3286.

[22] Hong, J. I., Chang, W. H., 1996, Reactions Kinetics of Lactic Acid with Methanol Catalyzed by Acid Resins", International Journal of Chemical Kinetics, 28:37-41.

[23] Yadav, G.D., Thathagar, M.B., 2002, Esterification of Maleic acid with Ethanol over cation exchange resin catalysts, Reactive Functional Polymer, 52:99-100. 